\title{
FIRMS' DYNAMIC CAPABILITIES: A CASE OF INDONESIAN TELECOMMUNICATION COMPANY
}

\author{
Sari Apriza ${ }^{1}$; Ami Fitri Utami \\ ${ }^{1,2}$ Management Program, BINUS Business School Undergraduate Program, Bina Nusantara University \\ Jl. K.H Syahdan No. 9, Palmerah, Jakarta 11480, Indonesia \\ ${ }^{1}$ sapriza@binus.edu; ${ }^{2}$ autami@binus.edu
}

\begin{abstract}
Based on the concept of dynamic capabilities that were introduced by Teece \& Pisano, this research aimed to analyze how did the dynamic capability condition in Company A. This research used a descriptive qualitative method of secondary data from annual report 2013 to 2017 and article in the website. It is found that Company A possesses a dynamically fluctuate dynamic capabilities through their ability to absorptive capability, adaptive capability, and innovative capability. The implementation of dynamic capabilities in Company A depend on top management board member to develop the company's general strategic move and by this able to maintain the dynamic capability, and Telecommunication company should be able to nurture the whole organizations' environment which supports the proliferation of this capability to all the members inside. In short, the benefit of this research will give learning point for the business player or practical to deal with the dynamic situation by using a dynamic capabilities perspective.
\end{abstract}

Keywords: absorptive capability, adaptive capability, innovative capability, dynamic capabilities

\section{INTRODUCTION}

The current business condition is constantly changing and often relates to a high-velocity and hypercompetitive environments which pushes organizations to be able to adapt with the resulted dynamism (D'aveni 1994; Bourgeois \& Eisendhardt, 1988). One of the examples is the current technological changes which have already disrupted various industries; from a stable low phase industry into a highly dynamic one. By this, organizations which are nurtured in a highly changing environment, are often coerced to create changes in order to adapt and re-act to attain and increase their performance (Eriksson, 2014; Barreto 2010). Discussing more the changes, these forms of dynamics also occur in the telecommunication industry. The emergence of the internet, digitization, and various mobile applications urge the market to shape a whole different consumption in communicating with each other. By this, company's strategies and innovations need to adapt not only to the competitions among players inside the industry but also to the evolving consumption trends and pattern from the consumers. Inevitably, being adaptable to the dynamics of business is imperative for a business to succeed.

Specifically discussing a business industry; certainly a firm with a greater capacity for change will have more strategic options than one that is more inert. Such flexibility is no doubt a good thing for an organization (Pisano, 2015). In this era, the telecommunication industry has been hustled with a sharp competition in Indonesia, and it needs the more strategic option. Indonesia currently possesses 83,5 million users of smartphone that variedly spread into numbers of mobile phones operators in the country's telecommunications industry (Katadata Indonesia, 2016). In this case, comparing to the total numbers of the national citizen, the use of smartphones is relatively slow which might be caused by the country's low internet connection. However, though the growths are slow, many sources claim that 
the numbers will keep increasing in the future due to the unexploited market opportunity. Moreover, the business focuses in the industry also changes. If in previous years the competitions are formed on the basis of voice and the short message service, today's provider competes to provide the best data services due to the changing market's needs and trends. This issue also drives the changes in how companies compete for each other.

In the industrial player, currently, there are four prominent players out of ten mobile phones operators in Indonesia includes TI, IO, H3I, and Company A. These prominent players are grasped up to $90 \%$ of total market shares in the industry (Indonesia-Investments, 2016). However, though the market shares seemingly dominated by only several players, the sharp competitions between those players still occur due to the slow growth of active mobile phone users. Hence, the tightness of the industry's competition is not only resulted in the number of players but also the constantly changing and evolving market needs and growth.

Based on the 2015 company's annual report, Company A as one of the prominent player in the telecommunication industry faces a highly turbulent business in the last five years. The sharp competition that includes the evolving market needs and almost saturated market leads the company to financial loss in almost three years consecutively from 2013 until 2015. The company struggles in facing the competition by doing various strategy from the products \& price modifications, company acquisitions, and several structural changes in its' governance and organization. However, from all strategies implemented by the company, the significant improvement comes out after the overall organization transformation strategy formed in early 2015 , which was led by an umbrella strategy and the 3R strategy (revamp, rise, reinvent). Seeing the company's trend in the last five years, Company A shows its ability to endure the competition by bouncing back the position from the loss to profits in the year 2016 and 2017.

This research aims to analyze the ability of Company A to face the dynamics in the industry's business using a perspective of dynamic capabilities. The concept of dynamic capabilities is introduced by Teece and Pisano in 1994 which is often synched as the extension of Penrose's Resource-Based View (RBV) view. Prominent scholars such Teece, Pisano, and Shuen (1997) have argued that dynamic capabilities describe a firm's ability to respond rapid change in business environment by systematically contrives, integrates, and reconfigures its internal and external competences. This capability is considered imperative to most firms' success in facing a dynamic condition. Lined with the Company A's case, the company is able to strike back its position positively within the highly competitive industry from the loss in the previous two years. By this, the research analyses on how this is company able to gain the dynamic capabilities that are imperative to be understood to enlighten managers who are managing in this industry.

The concept of dynamic capability is postulated as sets of company's ability to create, renew, and alter the competence to achieve competitive advantage and endured the business turbulences (Teece, Pisano, \& Shuen, 1997; Rufaidah \& Sutisna 2015). This concept is actually developed by Teece and Pisano (1994) that is often claimed as the extension to cover the RBV concept by Penrose in 1959 (Rufaidah \& Sutisna, 2015; Ambrossini \& Bowman, 2009). The dynamic capability and RBV framework are both taking notes on the importance of internal resources; however the RBV concept is mostly claimed unable to explain how the internal resources dynamically altered with current business issues (Ambrosini \& Bowman 2009). Discuss deeper about the definition, Teece in 1997 has claimed that company's dynamic capabilities may be depicted in its abilities to sense, seize, and reconfigure their knowledge, competencies, and complementary assets to achieve competitive advantage. Then after more research, Teece (2018) has mentioned that the dynamic capabilities include the sensing, seizing, and transforming needed to design and implement a business model. Figure 1 shows dynamic capabilities and strategy combine to create and refine a defensible business model which guides the organizational transformation. 


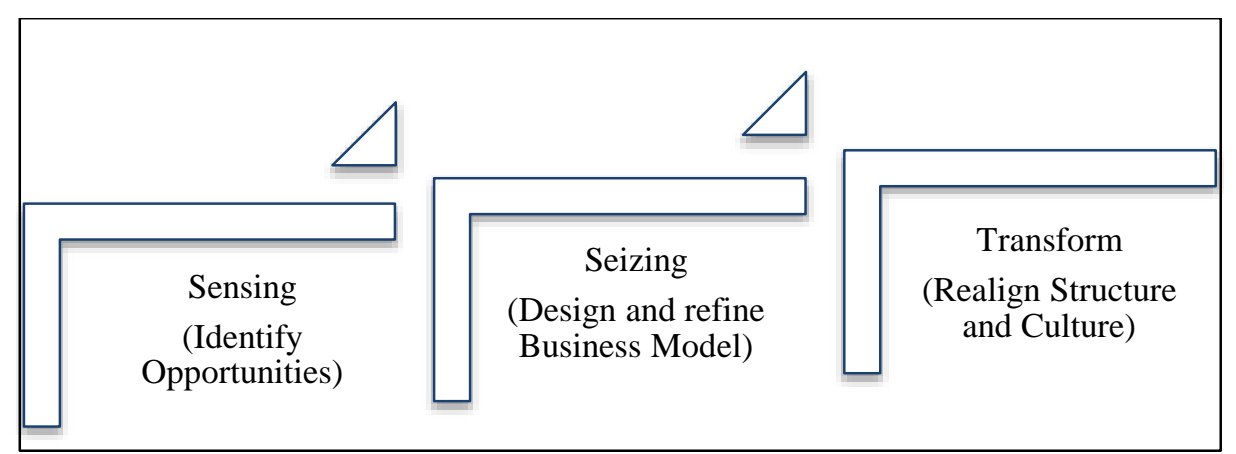

Figure 1 Dynamic Capability of Teece (2018)

Moreover, Wang and Ahmed (2007) have also contended that a dynamic capability is a form of firm's behavior to continually renew, integrate, and reconfigure its' capabilities and core competencies in response to the changing environment. By this, the firm's dynamic capabilities can be exerted into three classifications includes the capability to sense, seize opportunities and capacities to combine, and reconfiguring available assets on managing current and upcoming threats (Augier \&Teece, 2009). On the other hands, despite the discussed process components includes sensing, seizing, and reconfigure company's resources, Wang and Ahmed (2007) have claimed three capabilities which may obtain a company's dynamic capabilities. The first capability is the adaptive capability which means a company's capability to identify and capitalized the occurring opportunity in the market. In this context, the adaptive capability can be seen in the company's ability to response the opportunity, analyze market condition, as well as the condition of other competitors. Moreover, the second capability is the absorptive capability. In this context, the absorptive capability is defined as the ability of a company to recognize the value of new external information and utilize for commercial objectives. By this, Wang and Ahmed (2007) have claimed that absorptive capability can also be seen in the company's research and development activities. Moreover, the third capability is the innovative capability which seen as the company's ability to develop a product or a new market through innovative strategy. Figure 2 shows the dynamic capabilities of Wang and Ahmed (2007).

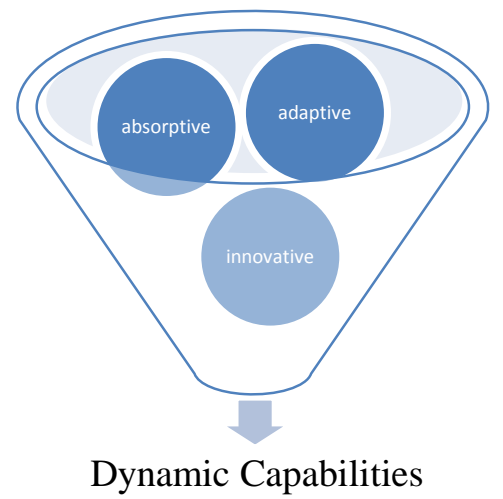

Figure 2 Dynamic Capabilities of Wang and Ahmed (2007)

From these discussions, dynamic capability then can be explained as the company's capability to use their current resources both to explore and adapt to the evolving business conditions externally. Despite varied views postulated by previous scholars which seen dynamic capabilities both as process or abilities, dynamic capabilities have claimed to have a role in shaping a company's competitive advantages not only in a high-velocity industry but also even in moderately dynamics one (Barreto, 
2010). By this, it is imperative to understand how companies acquire the dynamic capabilities as the learning points for another business player.

\section{METHODS}

This research uses the qualitative method to achieve its objectives. In this context, the perspective of dynamic capability by Wang and Ahmed (2007) will be used to describe Company A's dynamic capabilities. The application of Wang and Ahmed's components of dynamic capabilities is caused by the importance of those three factors to underpin the process of integrating, reconfiguring, and even renewing company's resources to the external changes (Wang \& Ahmed, 2007). By this, before going through the process perspective of dynamic capabilities as Teece \& Pisano (1997) views, the researchers will start with the factors to support those processes. On the other hands, besides using available secondary data in the company's websites and other sources which may relate with the research's objectives, this research also does an unstructured interview with one of the organization's member to gain internal insight.

\section{RESULTS AND DISCUSSIONS}

Company A is one of Indonesian telecommunication provider which started its operation in 1996. This company is then listed on the Indonesian Stock Exchange in 2005 which currently up to $33 \%$ owned by the public and the rest portion is owned by the concentrated investor. Up to present, through various strategies including the board restructuring process, Company $\mathrm{A}$ is also known as one of a leading companies in the industry. Discussing more about its organization, currently, Company A employs 1.892 employees which are relatively smaller than previous years. By this, there is some employment efficiency being done by the company to reduce the employees up to $6,94 \%$. In 2016 , three prominent businesses are being run by Company A namely the data and value-added services, voice and sms services, and infrastructure development.

Furthermore, after a year of loss, Company A introduces the transformation framework within three main strategies as their guidelines in early 2015 which are aimed to revamp, rise, and reinvent the business. In this case, these strategies have been acted as the company's pioneer to transform themselves after a huge fluctuated loss in previous years. Through these strategies, Company A is also able to aim for a better business position in the future years. In this context, Company A has the increase profits in 2016 and 2017 after the transformation agenda being applied.

Discussing more about the transformation strategy, revamping strategy means to move or shift their subscriber's acquisition from volume based to value based. Moreover, the rising up strategy aims to elevate the brand value by using a dual brand strategy using their product lines to strive for a different market segment. So last, the reinventing strategy is postulated to nurture the innovationfriendly culture in the company.

Absorptive capability in Company A is considered as ones' ability to learn and integrate others' information to become internal knowledge and utilize it for commercial uses (Rua \& Franca, 2016; Wang \& Ahmed, 2007). By this, companies with a higher absorptive capability will show their ability to acquire new knowledge from external information includes market and competitors dynamics. Hence, the higher one of absorptive capability shows the dynamic capabilities. On the other hands, the ideas of the absorptive capability of Wang and Ahmed (2007) show that several points can 
be seen to measure this capability and the appearance of new knowledge or innovation that is resulted by the assimilation of external information.

Based on to the company's case; there are some points from the organization which shows the possession of this capability. Through the organization structure, Company A develops a Competitive Intelligence division which aims to grab most information both from primary and secondary stakeholders to support the business strategy. In this context, the division acts to analyze various sets of data and information that are both acquired by the internal company and external third parties (i.e., data consultant) to help the company understands current situations includes revenue drops, increases, shifts, and others. However, this capability of Company A still heavily relies on the top management team. In this context, the top management team still acts as the key parties to decide which information is needed to be exposed and analyzed. Hence, even the activity of seeking the 'what's going on' information is treated seriously, and the priority of information analysis is still mostly decided by the top management of the company.

Moreover, due to the importance of top management and the board's role on the company's absorptive capability, Company A changes its boards' member several times especially within and after their crisis phases. In this context, based on the company's business plan guide year 2016 (internal source), Company A aims for a more agile board member to revamp their core business competitiveness. However, a question appears that do their strategies also project their absorptive capabilities. In answering this question, the researchers should also consider the time-span of the company's movement. In 2014, the company faced a huge loss until its third quarter of the year. This loss was caused by the integration cost of their acquisitions strategy and the volatility of global economic conditions.

However, right after knowing their loss, Company A then tried to develop the transformation actions which were implemented in early 2015. In this context, the ability of Company A to sense the condition and realize the needs of transformation may be considered as an act of absorptive capability. Unfortunately, their inability to avoid the proliferating cost caused by the acquisitions will show the opposite view. This is worsened by the fact that their loss is mostly caused by their internal business decision. Adaptive capability in Company A is considered as organization's ability to adapt through the firms' management activities which pushes its people to be able to change, evolve, and challenge old traditions or practices (Wang \& Ahmed, 2007; Gibson \& Birikinshaw, 2004). Moreover, this capability will show how fast the company is able to respond to the upcoming and current dynamics of its business.

In Company A, there are several iconic actions of the company which projected adaptive capability. In 2015, the transformation strategies implementation shows the company's attempt to change entire organization behavior by facing the absorbed information about the industry's trend. In this matter, these strategies are the company's game-changer to face the business. The transformation strategy consists of a strategy for revamping the core of their business, raising their value of the business, and re-inventing the way to play the game. By this, Company A admits to spreading this strategy as the company's transformation agenda to the whole organization.

Discussing more the adaptation, one of the contrast examples is the board members changes. Company A has changed its governance board and management board members several times through this past view years. This is one of the company's approaches to include new people in the top key positions in the company. As the company's yearly business plan quotes, "We are aimed for a more agile member of the governance board." By this, the company surely attempts to proliferate this capability through the structure of the top management and governance boards. Moreover, the company also attempts to focus the human resources development activity on nurturing a more adaptive and market-oriented culture. In today's business, the intended culture seems already proliferated in the company. This can be shown by the current company's sensitivity to daily 
transaction information recapitulation. In this context, the researchers' interview result shows that Company A will respond vastly when the numbers of consumer transactions are dropped in that moment. By this, the competitive intelligence division will act responsively to analyze what is happening on their market.

From the discussion, it can be concluded that Company A strategy which focused on the three main contexts is the form of company's adaptive capability which then encompasses by the company's actions from the boards change until culture change. On the other hands, Company A also does other actions includes logo transformation and various functional strategies like how to manage their financial portfolio, branding and marketing strategy, as well as elevate the quality of their people.

The innovative capability is the capability to be innovative that reflects a firms' ability to build something new includes products or markets. In Company A, the innovative capability can be gained by aligning the company's strategic orientations, behavior, and process (Wang \& Ahmed, 2007). It can be assumed that the company's strategy will strengthen or even weaken the company's innovative capability. Furthermore, in understanding the company's innovative capability, this research tries to analyze the forms of innovation launched by Company A through these years. The first category is the innovation of the new product. In 2016 the company results several innovations include mobile broadband solutions for family and business internet user, high-end priority product for the post-paid service, and various more innovative data plan packages. Moreover, the mentioned product innovations also aim to grab other market segments. For example, the mobile broadband solutions also grab a business and home internet user segment; on the other sides, Priorities' and Pass also aim to strive for a more exclusive market segment. These forms of innovation are all driven by the transformation strategy which aggressively intensified that the company needs to increase the value of their brand as well as their current and upcoming subscribers.

Move backward to the company's innovation in their years of loss; the company relies their innovation on the company's strategy to become the most super-low cost provider in 2014. In this context, during 2014 all of the innovations are in the form of efficiency. There is not much innovation done during this year except the launch of $4 \mathrm{G}$ LTE technology which is also done by other providers. In this vein, based on the company's annual report in 2014, the company is busy to handle their management condition in the post-acquisition phase which created the loss.

Based on the discussion, it can be seen that Company A's innovative capability relies on its strategy. The intense innovations which are done by the company are differed through the years due to the different strategy aimed at the top management level.

Todays' scholars consider current business condition as highly dynamic capability with various turbulences due to the emergence of many disruptions includes technological disruption. Company A as one of a big player in the telecommunication industry also faces the same kind of dynamics. In this case, the availability of digital innovation technology has shifted the company's market consumption into a whole different pattern (i.e., voice to data). In facing the dynamics, business obligates to be able to adapt with changes in order to survive. In this context, prior scholars contend the importance of dynamic capability concept to be possessed by most nowadays companies. Dynamic capability concept contends as sets of ability to create, renew, and alter own competence to endure the business turbulences. Moreover, in developing this capability, Wang and Ahmed (2007) claim that there are three prominent capabilities important to be owned by a company including absorptive, adaptive, and innovative capability.

Discussing Company A and its dynamic capability, the discussions in previous sessions already project how the company's concept. By this, the company's dynamic capability is not static and stable over time but more dynamically fluctuate depends on the company's general strategic intention which mostly developed by the top management. In this context, the researchers provide the 
scheme of the company's action which supports the prominent capabilities in the company's dynamic capability formation (see Figure 3).

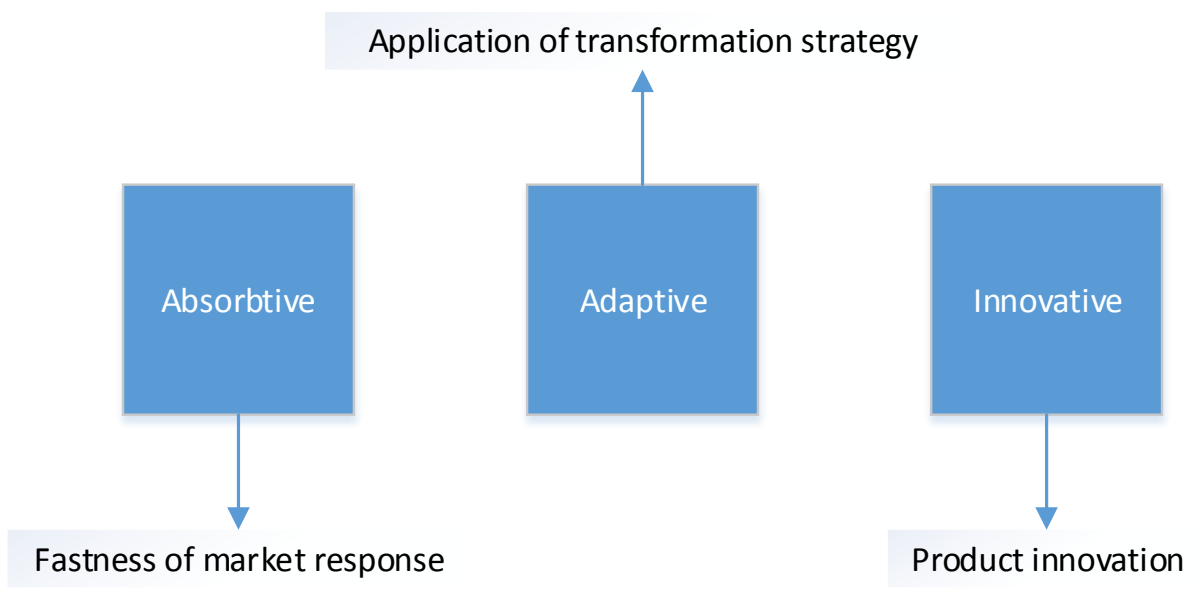

Figure 3 Dynamic Capability of Company A

However, despite its fluctuations, Company A can be considered to possess this capability; unfortunately, not all of the action that is resulted from this capability increases the company's performance. For example, in 2013 Company A decided to make the acquisition of other company in order to expand their capability to grab the wider market. This strategy can be seen as the company's adaptive capability due to that time business conditions; however this acquisition is one of the reasons which triggered the company's loss in 2014 and 2015. In contrary, in early 2015 the company decided to act for a transformation agenda named as through the three framework strategies. In this context, after those strategies act as a form of company's strategy to adapt to internal and external business issues in order to gain the company's profit back. This strategy, however, projects the company's dynamic capabilities include the absorptive, adaptive, and innovative capability.

\section{CONCLUSIONS}

The analysis concludes that Company A's dynamic capability is dynamically fluctuating which mostly relies on its top management board members who develop the company's general strategic move. In maintaining the dynamic capability overtimes, Company A should be able to nurture the whole organizations' environment which supports the proliferation of this capability to all the members inside. Hence, the strong dependence of this capability to the leader can be decreased if all organizations member possesses their own dynamic capability in doing their jobs in the business.

However, this research and suggestion also possess several forms of limitations. First, due to the time limitation, this research has a lack of direct internal information and mostly relies on the company's external news and annual reports. By this, to enhance the robustness of this research, a more extensive data gathering, and exploitation will be needed. Moreover, including the context of individual-level analysis (i.e., leader influence) in a more detailed manner will strengthen the premises that leader in Company A will influence the forming of dynamic capability inside the company. Hence, another method also can be used to enrich the analysis includes the quantitative method to determine the influence degree of leadership to the dynamic capability in Company A. 


\section{REFERENCES}

Ambrosini, V., \& Bowman, C. (2009). What are dynamic capabilities and are they a useful construct in strategic management? International Journal of Management Reviews, 11(1), 29-49.

Augier, M., \& Teece, D. J. (2009). Dynamic capabilities and the role of managers in business strategy and economic performance. Organization Science, 20(2), 410-421.

Barreto, I. (2010). Dynamic capabilities: A review of past research and an agenda for the future. Journal of Management, 36(1), 256-280.

Bourgeois, L. J., \& Eisenhardt, K. M. (1988). Strategic decision processes in high velocity environments: Four cases in the microcomputer industry. Management Science, 34(7), 816835 .

D'Aveni, R. A. (1994). Hypercompetition: Managing the dynamics of strategic maneuvering. New York: Free Press.

Eriksson, T. (2014). Processes, antecedents, and outcomes of dynamic capabilities. Scandinavian Journal of Management, 30(1), 65-82.

Gibson, C. B., \& Birkinshaw, J. (2004). The antecedents, consequences, and mediating role of organizational ambidexterity. Academy of Management Journal, 47(2), 209-226.

Indonesia-Investments. (2016). Telecommunication sector Indonesia: Saturated mobile phone market. Retrieved from https://www.indonesia-investments.com/id/news/todaysheadlines/telecommunication-sector-indonesia-saturated-mobile-phone-market/item7032?

Katadata Indonesia. (2016). Pengguna smartphone di Indonesia 2016-2019. Retrieved from http://databoks.katadata.co.id/datapublish/2016/08/08/pengguna-smartphone-di indonesia-2016-2019.

Pisano, G. P. (2015). A normative theory of dynamic capabilities: Strategy know how, and competition. Retrieved from https://www.hbs.edu/faculty/Publication\%20Files/16036_3be51325-1fb0-421a-afca-4571d958ebf9.pdf.

Rua, O. L., \& França, A. (2017). The linkage between intangible resources and export performance: The mediating effect of innovation. International Journal of Innovation, 5(3), 399-410.

Rufaidah, P., \& Sutisna. (2015). Kapabilitas dinamis UMKM industri kreatif Jawa Barat. Sosiohumaniora, 17(1), 60-66.

Teece, D. J., \& Pisano, G. (1994). The dynamic capabilities of firms: An introduction. Industrial and Corporate Change, 3(3), 537-556.

Teece, D. J., Pisano, G., \& Shuen, A. (1997). Dynamic capabilities and strategic management. Strategic Management Journal, 18(7). 509-533.

Teece, D. J. (2018). Business model and dynamic capabilities. Long Range Planning, 51(1), 40-49.

Wang, C., \& Ahmed, P. (2007). Dynamic capabilities: A review and research agenda. International Journal of Management Reviews, 9(1), 31-51. 